\title{
Patrick Barnes: Tail-end Charlie of the triathlon at 81
}

\author{
Carol Godsmark
}

"I am a very lazy man," Patrick Barnes, the 81 year old amateur athlete extraordinary asserts, sitting comfortably back in a winged chair in his West London home. Hardly, judging by the mass of cups and brightly coloured ribboned medals which cover his entire piano, all bearing testimony to $\mathrm{Mr}$ Barnes's remarkable participation in over 100 triathlons and 19 marathons.

Admittedly the octogenarian looks a little weary, but he has just returned from a twice weekly aerobics class, cycling the three miles there and back. A run will follow, hence the brief rest.

Patrick Barnes came across the triathlon-a combination of swimming, cycling, and running-when he consulted his physiotherapist for a knee injury he had suffered in a marathon.

"I was taken by her enthusiasm and signed up for my first triathlon at the age of 69 in 1984 at the Victoria Royal Docks in London," he grins, "and came last."

To date he has completed 81 of his 100 triathlons and still comes last. But he is firstand usually the only competitor-in his age group, which explains the medals and cups. But before the triathlon he had been inspired by the marathon, vowing to "have a go" when he could find the time. The moment only came when he retired and he started running.
"I started with 200 yards, then a mile, and by 18 months I was able to do the distance required for the marathon," he explains.

$\mathrm{Mr}$ Barnes competed in five New York marathons and one in Greece before coming across the triathlon.

His bike was 60 years old, a Raleigh nicknamed Beelzebub which his father had bought for him, despairing of his unathletic son whose main interests were Greek myths. Pluto, a 12 gear Dawes, now takes the strain and $\mathrm{Mr}$ Barnes will compete in a number of triathlons this year, from Scotland to southern England.

At a recent north of England triathlon, "Tail end Charlie," as Mr Barnes is affectionately known in the sport, was way behind, struggling with Pluto on a car clogged dual carriageway, unable to snake through the traffic to rejoin the other competitors who had passed this way some considerable time before. Lancashire police came to his rescue, police siren parting the waves and Tail end Charlie pushed through. Last as usual.

Why does he compete? "I have no particular strength in any of the three sports and it started out as fun during retirement. A marvellous way to see the countryside too," he explains.

He would prefer a different ending though, to all the competitions he enters. "I would just like to finish them all," says the ever keen and modest Mr Barnes, rising from his comfortable chair to change his shoes for a run in the park. 